\title{
Role of angiotensin-converting enzyme in myeloid cell immune responses
}

Duo-Yao Cao ${ }^{1}$, Suguru Saito ${ }^{1}$, Luciana C. Veiras ${ }^{1}$, Derick Okwan-Duodu ${ }^{1,2}$, Ellen A. Bernstein ${ }^{1}$, Jorge F. Giani ${ }^{1,2}$, Kenneth E. Bernstein ${ }^{1,2}$ and Zakir Khan ${ }^{1,2^{*}}$ (D)

\author{
* Correspondence: zakir.khan@csmc. \\ edu \\ ${ }^{1}$ Department of Biomedical \\ Sciences, Cedars-Sinai Medical \\ Center, Los Angeles, CA 90048, USA \\ ${ }^{2}$ Department of Pathology and \\ Laboratory Medicine, Cedars-Sinai \\ Medical Center, Davis Res. Bldg., \\ Rm. 2014, 8700 Beverly Blvd, Los \\ Angeles, CA 90048, USA
}

\begin{abstract}
Angiotensin-converting enzyme (ACE), a dicarboxypeptidase, plays a major role in the regulation of blood pressure by cleaving angiotensin I into angiotensin II (Ang II), a potent vasoconstrictor. Because of its wide substrate specificity and tissue distribution, ACE affects many diverse biological processes. In inflammatory diseases, including granuloma, atherosclerosis, chronic kidney disease and bacterial infection, ACE expression gets upregulated in immune cells, especially in myeloid cells. With increasing evidences connecting ACE functions to the pathogenesis of these acquired diseases, it is suggested that ACE plays a vital role in immune functions. Recent studies with mouse models of bacterial infection and tumor suggest that ACE plays an important role in the immune responses of myeloid cells. Inhibition of ACE suppresses neutrophil immune response to bacterial infection. In contrast, ACE overexpression in myeloid cells strongly induced bacterial and tumor resistance in mice. A detailed biochemical understanding of how ACE activates myeloid cells and which ACE peptide(s) (substrate or product) mediate these effects could lead to the development of novel therapies for boosting immunity against a variety of stimuli, including bacterial infection and tumor.
\end{abstract}

Keywords: Angiotensin-converting enzyme, Myeloid cells, Immune response, Neutrophils, Macrophages, Dendritic cells, Hematopoiesis, Methicillin-resistant Staphylococcus aureus (MRSA), Melanoma, MHC class I antigen presentation

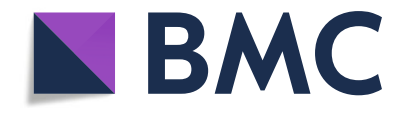

This article was specially invited by the editors and represents work by leading researchers.

\section{Introduction}

The renin-angiotensin system (RAS) is a major regulator for blood pressure, fluid and electrolyte balance, in which sequential action of two enzymes, renin and ACE produce a bioactive peptide angiotensin II (Ang II) $[1,2]$. It is well established that RAS, via the Ang II AT1 receptor, plays a crucial role in cardiovascular and renal functions by regulating blood pressure, electrolyte and volume homeostasis [2, 3]. This traditional concept of the RAS as a circulating endocrine system has been evolved enormously with time and many new RAS-regulatory components including peptide molecules, enzymes and G protein-

\footnotetext{
(C) The Author(s). 2020 Open Access This article is licensed under a Creative Commons Attribution 4.0 International License, which permits use, sharing, adaptation, distribution and reproduction in any medium or format, as long as you give appropriate credit to the original author(s) and the source, provide a link to the Creative Commons licence, and indicate if changes were made. The images or other third party material in this article are included in the article's Creative Commons licence, unless indicated otherwise in a credit line to the material. If material is not included in the article's Creative Commons licence and your intended use is not permitted by statutory regulation or exceeds the permitted use, you will need to obtain permission directly from the copyright holder. To view a copy of this licence, visit http://creativecommons.org/licenses/by/4.0/.
} 
coupled receptor have been identified [4-7]. The development of ACE inhibitors (ACEi, eg. enalapril, captopril, lisinopril, ramipril) or AT1 (Angiotensin II receptor type 1) blockers (ARBs, eg. losartan) not only revolutionized the treatment strategies to treat hypertension, but also provided a tool for the discovery of many unknown functions of ACE components in different physiological and pathological mechanisms.

Increasing number of studies suggest that, in different tissues, a local RAS may operate either systemically or entirely independent to the circulating counterpart, and it may act as a whole or in part to meet the specific needs of the individual tissues via autocrine and/or paracrine pathways [8,9]. For example, in bone marrow (BM), it affects critical steps of blood cell production, such as hematopoietic niche [10], myelopoiesis [11], and the development of other cellular lineages including lymphocytic [12]. There are also enough studies suggesting local operation of RAS in other organs including cardiac, vascular and renal tissues [13-17].

Renin enzyme is highly specific and extremely limited in its tissue expression, while ACE is relatively nonspecific and widely expressed in different tissues [5]. Other than Ang I, ACE can cleave variety of substrates including bradykinin, substance P, tetrapeptide $\mathrm{N}$-acetyl-seryl-aspartyl-lysyl-proline (AcSDKP), enkephalins, neurotensin and others. Because of this wide tissue distribution and substrate specificity, ACE may affect many diverse biological functions, including renal development, fertility, hematopoiesis and immunity $[5,18,19]$. This review aims to discuss new biological functions of ACE in different aspects of the immune response.

\section{ACE and immunoinflammatory diseases}

Inflammation plays a critical role in immune activation. Many studies have found ACE to be a potent pro-inflammatory modulator [20] that plays a role in the recruitment of inflammatory cells into tissues by regulating chemokines and adhesion molecules [21]. ACE not only functions as a cell membrane ectopeptidase, but it can be secreted into extracellular milieu by activated myelomonocytic or other lineage cells, and thus, it act as both local and systemic regulator of peptides [22]. The association of ACE with immunoinflammatory diseases has been well established. First report published in 1975 that showed higher serum ACE in patients with sarcoidosis. Now, it is known that circulating ACE is elevated in many other granulomatous diseases, such as Gaucher's disease and tuberculosis [23, 24]. In sarcoidal granulomas the increased ACE activity is predominately contributed by epithelioid cells and macrophages of the granuloma, and a higher serum level of ACE is observed in a majority of patients [25]. In tuberculosis granuloma, increased ACE is mostly contributed by alveolar macrophages [26].

Based on CD14 and CD16 expression, monocytes can be divided into two subpopulations Mo1 and Mo2. Percentage of Mo2 increased in many inflammatory diseases including chronic kidney disease (CDKs), which expresses higher level of ACE along with CD14 and CD16 [17, 27]. These monocytes are proinflammatory in nature and associated with increased atherosclerosis and cardiovascular mortality in hemodialysis patients [28]. It is now believed that all RAS components express in immune cells. For example, monocytes and macrophages express renin, ACE, Ang I and Ang II, AT1 and AT2 receptors [29]. In nervous system also, all RAS components are locally synthesized by different cell types, including astrocytes, microglia and neutrons [30, 31], and ACE expression is increased in many neurological autoimmune diseases including 
encephalitis and multiple sclerosis $[18,32]$. There is no clear understanding why ACE expression increases in these immunoinflammatory conditions. One possibility is that ACE activity increases the activation of immune cells in response to immune challenge.

\section{ACE in hematopoiesis and myeloproliferation}

$\mathrm{BM}$ is a complex and highly organized system that produces all circulating cells. However, hematopoiesis is tightly regulated by a variety of factors including enzymes, receptors, hormones, cytokines, growth factors and bioactive peptides. The early clues about the RAS effects on hematopoiesis came from the reduced hematocrit of patients, who were treating with the ACEi enalapril [33]. Studies further suggested that enalapril caused erythrocytosis in patients with renal transplantation by reducing the hematocrit level $[34,35]$. In rare patients, ACEi treatment also causes anemia due to its effects on immune system [36]. In clinical studies, people find that ACEi suppress RBC production and decrease white blood cells In clinical studies [37, 38]. These finding clearly hypothesize a possible role of the RAS in hematopoiesis. Over time, all the known components of the RAS, such as angiotensinogen, renin, ACE, AT1a, AT2 (Angiotensin II receptor type 2), Mas (G protein-coupled receptor) and ACE2 (Angiotensin converting enzyme 2), have been identified in the BM, and it is now believed that local RAS operates in the BM $[8,39]$. These RAS components, particularly ACE-mediated peptides, affect several critical steps of hematopoietic cell development in physiological and pathological conditions $[8,9,39]$.

The existence of ACE in primitive lympho-hematopoietic cells, embryonic and fetal tissues suggests that ACE not only affects erythropoietic progenitors, but might have effects on neoplastic tissues and primitive pluripotential hematopoietic stem cell populations [40, 41]. The ACE substrate Ac-SDKP has been extensively studied in the regulation of stem cell proliferation. ACE inhibition by enalapril increases the level of Ac-SDKP in both plasma and BM $[42,43]$, which in turn prevents hematopoietic stem cell proliferation [44]. In the BM, stromal cells produce a large amount of Ac-SDKP [43], and the increased ACE expression in stromal cells significantly decreases the AcSDKP level in the BM microenvironment. Rousseau-Plasse et al. (1996) demonstrated that ACE plays an important role in the recruitment of primitive stem cells into Sphase by hydrolyzing Ac-SDKP [45]. Comte and colleagues then observed significant changes in the circulatory hematopoietic progenitors in healthy volunteers following administration of enalapril. It increased plasma and urinary Ac-SDKP in association with an increased number of mixed colony-forming unit (mixed-CFU) hematopoietic progenitors, and in contrast, reduced the number of granulocyte-monocytic colonyforming unit (CFU-GM) and Burst-forming unit-erythroid (BFU-E) hematopoietic progenitors in the circulation [46]. Ang II is another important peptide of ACE implicated in hematopoietic cell development. AT1 receptor is expressed by $\mathrm{CD} 34^{+}$hematopoietic progenitors and stromal cells in human tissues [47]. By binding to AT1a receptor on $\mathrm{CD}^{+}{ }^{+}$hematopoietic stem cells, Ang II increases proliferation of these cells [47]. Further study validated that ACE inhibition by captopril caused myelosuppression by inhibiting stem cell and progenitor cell proliferation rather than depleting the BM cells [48]. These studies suggest that ACE has a regulatory role in hematopoiesis. 
There is now abundant evidence that ACE affect myelopoiesis. These data come from genetically modified mice with either ACE knockout (KO) or selective overexpression of ACE in myeloid cells. Absence of ACE suppresses differentiation of myelomonocytic precursors in ACE KO mice [11]. These mice showed a higher percentage of immature myeloid precursors including myeloblasts, myelocytes, and metamyelocytes as compared to WT mice. In contrast, a significant reduction of mature neutrophils was found in ACE-KO BM as compared to WT BM [11]. A dramatic reduction in nucleated erythroid precursors was found in the BM of ACE KO mice leading to anemia as compared to WT mice. ACE inhibition also increases early BM progenitors, such as LSK cells (a fraction enriched for hematopoietic stem cells) in ACE KO mice BM [11]. In addition, increased extramedullary hematopoiesis was found in the spleen that caused an expansion of immature myeloid cells in ACE KO mice as compared to WT [11]. Similar myelopoiesis abnormalities were observed by pharmacologic inhibition of ACE in mice. In conclusion, these data suggest that ACE knockout enhanced myeloproliferation with reduced differentiation that ultimately increased the number of immature myelomonocytic lineage cells in mice (Fig. 1).

\section{ACE and myeloid cell immune response}

Myeloid cells are a heterogenous population derived from a common myeloid progenitor that belongs to the innate immune system. As a first line of defense, myeloid cells (neutrophils, macrophages, and dendritic cells) are recruited to the inflammatory site and elicit a variety of immune responses to eliminate potential threats from outside and inside. Also, macrophages and dendritic cells (DCs) function as classical antigen presenting cells (APCs), therefore, these cells are crucial for the initiation of an adaptive

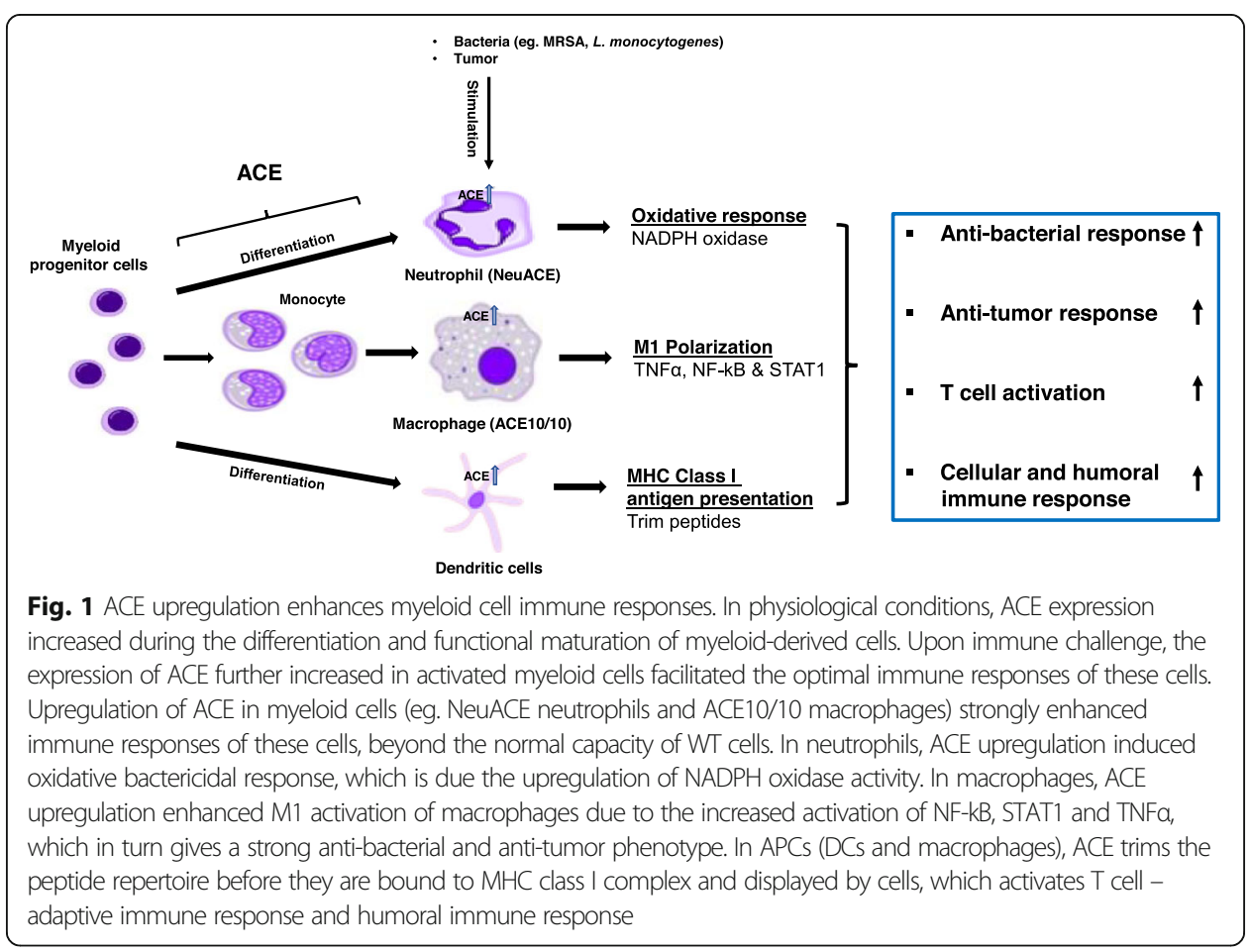


immune response. There is now strong evidence that ACE facilitates the immune activation of myeloid cells, as discussed below (Fig. 1).

\section{Neutrophil immune response}

Neutrophils, also called polymorphonuclear leucocytes, are an essential component of the innate immune response which plays a major role during acute inflammation [49]. In blood, mature neutrophils are derived from the BM with the goal to locate and kill harmful invading pathogens [50]. In a lipopolysaccharide (LPS)-induced acute lung inflammation mouse model, when mice were pre-treated with the ACEi enalapril, it reduced pulmonary recruitment of neutrophils following LPS treatment [51]. This may demonstrate that ACE could assist in neutrophil recruitment during pulmonary inflammation.

As protein expression markedly changes in activated neutrophils, we evaluated the expression of ACE in neutrophils following methicillin-resistant Staphylococcus aureus (MRSA) challenge. ACE expression upregulated in neutrophils upon activation with MRSA [52]. To study whether ACE expression is associated with immune functions of neutrophils, ACE KO and WT mice were subcutaneously challenged with MRSA and then mice were sacrificed day 3 post-infection. ACE knockout significantly reduced bacterial resistance in mice as manifested by larger lesion size (Fig. 2) and higher tissue bacterial burden in ACE KO mice as compared to WT mice. To directly access the effect of ACE on neutrophil activity, intracellular bacterial killing by purified ACE KO and WT neutrophils were determined. The intracellular killing of bacteria was significantly higher by WT neutrophils as compared to ACE KO neutrophils [52].

Because the lack of ACE expression is linked with neutrophil immune suppression, we also investigated the phenotype of animals overexpressing ACE in neutrophils. To study this, a transgenic mouse line called NeuACE mice was generated by using a cfms-ACE construct [52]. These mice overexpress ACE ( 10 fold $)$ in neutrophils. In contrast to ACE KO, NeuACE mice show enhanced resistance to bacterial infections as compared to WT mice [52]. To investigate the role of Ang II, mice were pre-treated

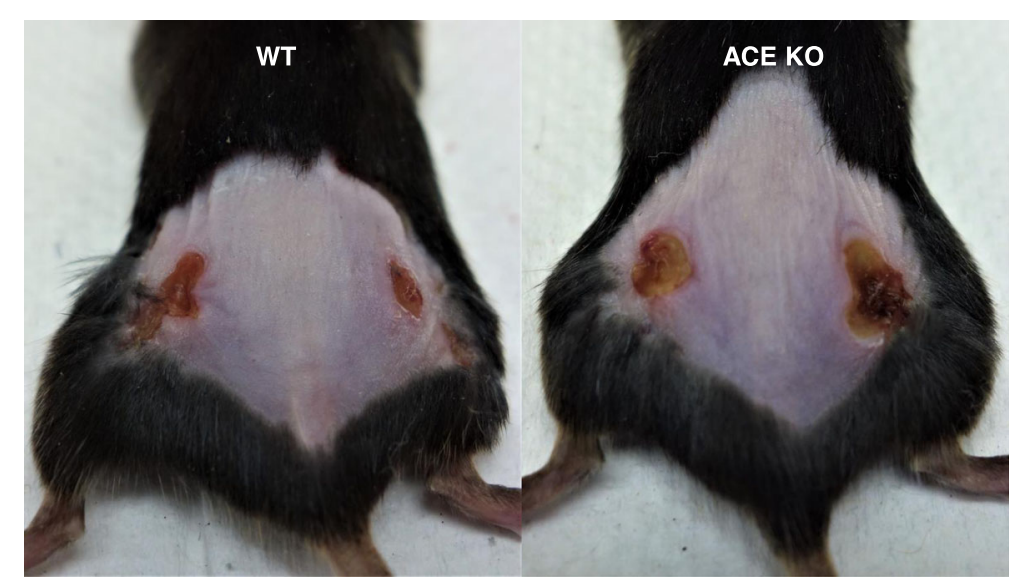

Fig. 2 ACE affects anti-bacterial defense. In mice, ACE knockout suppressed bacterial resistance. Representative images showing MRSA skin lesion at day 4 post-bacterial subcutaneous injection $\left(1 \times 10^{7} \mathrm{CFU} /\right.$ mouse flank $)$ [Cao D-Y et al. Unpublished data] 
with either the losartan (ARB) or ramipril (ACEi) for several days before infection. Ramipril treatment eliminated any differences between NeuACE and WT mice. In contrast, losartan had no major effect [52]. This indicates that AngII-AT1R does not mediate ACE effect on neutrophil antibacterial activity. By using renin inhibitor and Ang II infusion in mice, we confirmed that no Ang peptide mediates neutrophil-ACE effects. Further, the phenotype of ACE overexpressing NeuACE neutrophils appears independent of AcSDKP, bradykinin-B2K receptor and substance P-NK1 receptor [52]. Sometimes, treatment with ACEi caused angioedema (a mucosal immunopathological condition) in patients due to inhibition of kinin degradation and consequent inhibition of kinin-B1KR signaling pathway [53, 54]. However, the role of B1KR in neutrophil immune response needs to be investigated.

The production of reactive oxygen species (ROS) is very important for neutrophil antimicrobial activity. We found that ACE directly affects ROS production in neutrophils. Upon immune challenge, ACE KO neutrophils produce less ROS, while NeuACE neutrophils produce more ROS as compared to WT neutrophils (Fig. 1). Further, our study demonstrated that ACE increases neutrophil antibacterial activity by enhancing NADPH oxidase enzyme activation, an effect that is independent of the angiotensin II AT1 receptor [52].

ACEi are generally considered safe and used by millions of patients for the treatment of hypertension and cardiovascular diseases. As ACE plays an important role in neutrophil anti-bacterial activity, any neutrophilic immune suppression by ACEi may increase risk of infection in vulnerable patients, such as patients with weak immunity. Indeed, some clinical studies have found an association between the uses of ACEi and increased risk of infection including sepsis and urinary tract infection [55-57]. Such infections were not noted with an ARB [57]. Therefore, our findings caution in the use of ACEi under conditions where patients are vulnerable to infections. The uses of ACEi and risk of infection needs to be further investigated.

\section{Macrophages immune response}

Macrophages as major residential innate cells can be found in many tissues and organs. They play a variety of roles in innate immune responses, such as phagocytosis, cytokine secretion, and antigen presentation etc. As mentioned above, increased ACE expression in granulomas was predominately contributed by epithelioid cells and macrophages. Also, ACE was upregulated during monocyte differentiation into macrophages in both the THP-1 cell line cultured with adipocyte-derived lipids [58] and in human peripheral blood $[59,60]$. Under uremic conditions, up-regulation of ACE in primary monocytes and THP-1 cells enhanced differentiation of these cells to macrophages with induced expression of proinflammatory cytokines, adhesion and transmigration molecules [61]. In mice, ACE upregulation was found in macrophages and DCs following MRSA or Listeria monocytogenes (L. monocytogenes) infection [62, 63] (Fig. 1). These findings show link between ACE upregulation and the activation of myeloid cells. What remained unknown was whether ACE upregulation also contributed in enhancing immune responses of these cells. To study this, Dr. Shen and colleagues developed a recombinant mice line, called ACE10/10 that overexpressed ACE in macrophages [62]. 
Anti-bacterial response To study macrophage innate immune response, the resistance of the ACE10/10 mice to MRSA or L. monocytogenes was determined [63]. For MRSA infection, mice were challenged subcutaneously, and then at day 4, mice were sacrificed and skin lesion size and lesional bacterial number were determined. ACE10/ 10 mice showed strong resistance to MRSA infection, as manifested by smaller lesion size and significantly lower lesional bacteria count as compared to WT mice. ACE10/ 10 mice also showed resistance to L. monocytogenes; a significantly lower tissue bacteria count (spleen and liver) was found in ACE 10/10 mice as compared to WT mice [63]. In addition, a reduction of necrosis and abscess formation in ACE10/10 mice further validated bacterial resistance in these animals as compared to WT mice. These differences between ACE10/10 and WT mice were not due to the Ang II AT1 receptor, as there was no effect of losartan treatment [63]. Furthermore, in vitro study with peritoneal macrophages showed that ACE does not participate directly in bacterial killing because without priming with interferon-gamma (IFNY), no difference was found between ACE10/10 and WT macrophages [63]. Nitric oxide (NO) is critical for a macrophage anti-microbial response to L. monocytogenes and MRSA. It was found that ACE upregulation increased NO production in macrophages leading to an improved immune response to bacterial infection [63].

Anti-tumor response Macrophages are not only important for the initial innate immune response but also play a crucial role in the initiation of the adaptive immune response by functioning as APCs and activating T cells. Shen et al. (2007) investigated macrophage anti-tumor response in relation to ACE expression [62]. They found that ACE overexpression in macrophages increased tumor resistance in mice. B16-F10 melanoma growth was significantly lower in ACE10/10 mice as compared to WT mice (Fig. 1). This tumor resistance in ACE 10/10 mice was dependent on increased number of tumor epitope-specific $\mathrm{CD} 8^{+} \mathrm{T}$ cells, as depletion of $\mathrm{CD}^{+} \mathrm{T}$ cells led to rapid tumor growth in ACE 10/10 mice [62].

ACE consists of two independent catalytic domains (N- and C-domains) [5]. To study the specific role of each domain, transgenic mice were generated, which overexpressed either WT ACE (Tg-ACE mice) or ACE lacking N- or C-domain catalytic activity (Tg-NKO and Tg-CKO mice) in myeloid cells. Tg-ACE and Tg-NKO mice strongly suppressed the growth of melanoma. In contrast, $\mathrm{Tg}$-CKO mice resist melanoma no better than WT mice (Fig. 3) [64]. Thus, this study shows that the overexpression of ACE C-domain by macrophages is a strong mechanism to increase resistance to tumor. Ang II is a very important peptide generated by the C-domain of ACE [5]. To study whether the Ang II-AT1 axis mediates tumor resistance, tumor growth was determined in mice pre-treated with losartan before tumor implantation. However, we found no significant effect of losartan on tumor growth suggesting this pathway does not participate in ACE mediated tumor resistance in mice. Further, blocking other known ACE Cdomain peptide pathways, such as bradykinin-B2R and substance P-NK1R, had no effect on tumor growth in mice [64].

It is found that up-regulation of ACE C-domain induced M1 signals in macrophages, including activation of tumor necrosis factor alpha (TNF $\alpha$ ), nuclear factor kappa-lightchain-enhancer of activated B cells (NF-kB), and signal transducer and activator of 


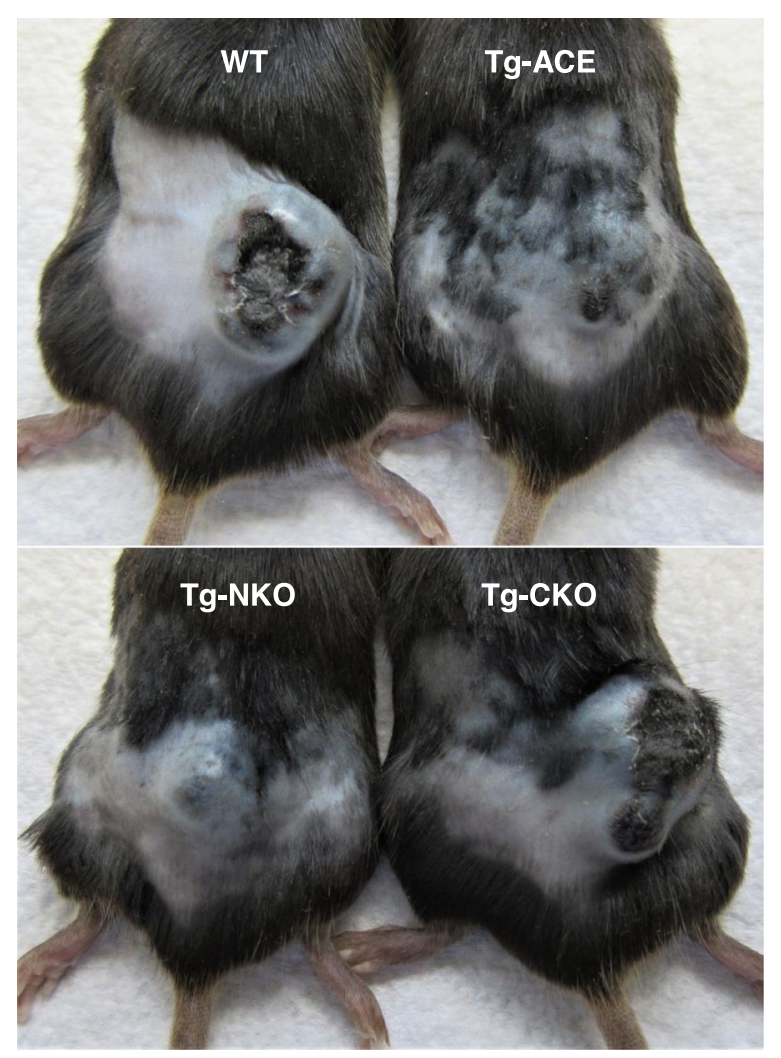

Fig. 3 Melanoma tumor growth. In mice, overexpression of ACE C-domain enhanced macrophage antitumor activity. Representative images showing tumor growth at day 14 after intradermal injection of B16F10 melanoma cells ( $10^{6}$ cells/mouse) [Cao D-Y et al. Unpublished data]

transcription 1 (STAT1), and in contrast inhibition M2 signals including STAT3 and STAT6 was found. This appears to reprogram these cells towards a more classically activated M1 phenotype that is responsible for the enhanced tumor resistance (Fig. 1) [64].

Metabolic effects Metabolic reprogramming is closely associated with the polarization of macrophages [65]. For example, LPS dependent inflammation by M1 macrophages mostly relies on glycolysis and fatty acid biosynthesis. In contrast, tissue repair activity by M2 macrophages switches their metabolism to fatty acid oxidation and oxidative phosphorylation [65]. To investigate the molecular basis of how ACE affects cells phenotypically, metabolism of ACE overexpressing myeloid cells (ACE10/10 and NeuACE) was determined. It was found that ACE up-regulation significantly increased ATP, Krebs cycle intermediates and electron transport chain proteins (NDUFB8, ATP5A, and ATP5 $\beta$ ) in ACE10/10 macrophages and NeuACE neutrophils as compared to WT cells [66]. This appears to underpin some of the phenotypic differences between these cells and myeloid cells expressing WT levels of ACE, such as superoxide production and phagocytic bacterial killing. Consistent with anti-tumor response, the Cdomain of ACE predominately enhanced ATP production in these cells. Again, there was no effect of Ang II on myeloid cell ATP production [66]. 


\section{Dendritic cells and adaptive immune response}

ACE is also expressed by dendritic cells (DCs) $[67,68]$. Ang II and bradykinin have been implicated in DCs maturation and Th1 cell development in a mouse model of Trypanosoma cruzi infection [69]. ACE expression increased during the differentiation of DCs and was further increased when these cells were activated with the proinflammatory cytokine IFN- $\gamma$ [70]. Similarly, when mice were challenged with listeria, ACE expression was up in splenic macrophages and DCs [70]. Major histocompatibility complex (MHC) class I proteins play a critical role in the activation of $\mathrm{CD}^{+} \mathrm{T}$ cell adaptive immune responses against intracellular pathogens and perhaps also against tumors. APCs, such as DCs and macrophages phagocytize cellular debris and present MHC class I bound antigens for CD8+ T cells. Mice studies suggest that ACE can trim the peptide repertoire displayed on the surface of APCs as part of the MHC class I complex (Fig. 1) [70, 71].

In addition to myeloid cells, ACE also plays a role in the activation of lymphoid cells. Hoch et al. (2009) found a direct autocrine effect of ACE and Ang II on T cell function, including activation, expression of tissue-homing markers, and production of cytokines [72], probably due to superoxide production by $\mathrm{T}$ cell NADPH oxidase. In a rodent model of cerebral malaria, following activation by infection, $\mathrm{T}$ cells show a significant increase of CD69 expression, while this reduced to normal when mice were treated with losartan and captopril [73]. In a clinical study of pulmonary sarcoidosis, the percentage of lymphocytes and the CD4/CD8 ratio in bronchoalveolar lavage fluid (BALF) is coordinated with ACE activity [74]. Further, a connection between Th1 cell cytokines (IL-12 and IL-18) and ACE activity was determined in BALF [75]. ACE and Ang II have also been implicated in encephalitis [17]. All these findings suggest an active participation of ACE in adaptive immune activation. Unfortunately, the critical ACE function and catalytic substrates are still obscure and need more investigation.

\section{Conclusions}

ACE is one of the most vital and well-studied peptidases in the RAS. However, in recent years, ACE functions are found to coordinate with immune responses. ACE is upregulated in many immunological diseases, such as granuloma. Similarly, upregulation of ACE was reported in myeloid cells following immune challenges. By comparing ACE $\mathrm{KO}, \mathrm{WT}$ and ACE overexpressing neutrophils and macrophages, our studies have demonstrated that ACE not only plays a physiological role in myeloid cell immune response, but if overexpressed, ACE further enhances immune responses against a variety of stimuli, such as bacterial infection and tumor, which is beyond the normal ability of WT cells. However, whether ACE overexpression has similar effects on human myeloid cells needs to be investigated. In both tumor and infection studies with transgenic mice overexpressing only an active $\mathrm{C}$-domain or an active $\mathrm{N}$-domain, we found that the $\mathrm{C}$ domain of ACE is important for increasing the immune responses of myeloid cells. However, none of the known ACE C-domain peptides, such as all angiotensin peptides, bradykinin and Substance p were found to mediate these ACE effects on neutrophils and macrophages. Identification of ACE peptide(s) (substrate or product) that elicit an increased immune response may hold great promise for therapeutic manipulation to boost the immune response against a variety of stimuli, including infections and tumors. 


\section{Abbreviations}

ACE: Angiotensin-converting enzyme; RAS: Renin-Angiotensin System; Ang II: Angiotensin II; ACEi: ACE inhibitors; ARBs: AT1 blockers; BM: Bone Marrow; AcSDKP: Tetrapeptide N-Acetyl-Seryl-Aspartyl-Lysyl-Proline; WT: Wild type; ACE KO: ACE Knockout; NeuACE: Neutrophil ACE overexpression; Tg-ACE: Transgenic ACE; Tg-CKO: Transgenic ACE C domain knockout; Tg-NKO: Transgenic ACE N domain knockout; APCs: Antigen Presenting Cells; DCs: Dendritic Cells; LPS: Lipopolysaccharide; MRSA: Methicillin-Resistant Staphylococcus aureus; L. monocytogenes: Listeria monocytogenes; IFNY: Interferon-gamma; NO: Nitric oxide; TNFa: Tumor Necrosis Factor alpha; NF-KB: Nuclear Factor Kappa-light-chainenhancer of activated B cells; STAT: Signal Transducer and Activator of Transcription; MHC: Major Histocompatibility

Complex; BALF: Bronchoalveolar Lavage Fluid

\section{Acknowledgements}

The authors thank Brian Taylor of Cedars-Sinai Medical Center for providing administrative helps during our studies.

\section{Availability of data and material}

Not Applicable.

\section{Authors' contributions}

All authors substantially contributed to the discussion of the content. S.S., L.C.V. E.A.B., and Z.K. researched data for the article. D.-Y.C., D. O.-D., J.F.G., K.E.B. and Z.K. drafted and edited the manuscript before submission. L.C.V. and Z.K. revised the manuscript. The author(s) read and approved the final manuscript.

\section{Funding}

This work was supported by American Heart Association (AHA) Grants 19 CDA34760010 (Z.K.), 17GRNT33661206 (K.E.B.), 16SDG30130015 (J.F.G.), and the National Institutes of Health Grants P01HL129941 (K.E.B.), R01Al143599 (K.E.B.), R01HL142672 (J.F.G.).

\section{Ethics approval and consent to participate}

All animal experiment protocols were approved by the Cedars-Sinai Institutional Animal Care and Usage Committee (IACUC No. 4978).

\section{Consent for publication}

Not Applicable.

\section{Competing interests}

No conflicts of interest, financial or otherwise, are declared by the authors.

Received: 20 January 2020 Accepted: 5 May 2020

Published online: 25 May 2020

\section{References}

1. Peart WS. Renin-angiotensin system. N Engl J Med. 1975;292(6):302-6.

2. Nishimura H. Renin-angiotensin system in vertebrates: phylogenetic view of structure and function. Anat Sci Int. 2017; 92(2):215-47.

3. Chappell MC. Biochemical evaluation of the renin-angiotensin system: the good, bad, and absolute? Am J Physiol Heart Circ Physiol. 2016;310(2):H137-52.

4. Jones ES, Vinh A, McCarthy CA, Gaspari TA, Widdop RE. AT2 receptors: functional relevance in cardiovascular disease. Pharmacol Ther. 2008;120(3):292-316.

5. Bernstein KE, Ong FS, Blackwell WL, Shah KH, Giani JF, Gonzalez-Villalobos RA, et al. A modern understanding of the traditional and nontraditional biological functions of angiotensin-converting enzyme. Pharmacol Rev. 2013;65(1):1-46.

6. Bernstein KE, Shen XZ, Gonzalez-Villalobos RA, Billet S, Okwan-Duodu D, Ong FS, et al. Different in vivo functions of the two catalytic domains of angiotensin-converting enzyme (ACE). Curr Opin Pharmacol. 2011;11(2):105-11.

7. Savoia C, Burger D, Nishigaki N, Montezano A, Touyz RM. Angiotensin II and the vascular phenotype in hypertension. Expert Rev Mol Med. 2011;13:e11.

8. Haznedaroglu IC, Ozturk MA. Towards the understanding of the local hematopoietic bone marrow renin-angiotensin system. Int J Biochem Cell Biol. 2003;35(6):867-80.

9. Haznedaroglu IC, Beyazit Y. Pathobiological aspects of the local bone marrow renin-angiotensin system: a review. J Renin-Angiotensin-Aldosterone Syst. 2010;11(4):205-13.

10. Hubert C, Savary K, Gasc JM, Corvol P. The hematopoietic system: a new niche for the renin-angiotensin system. Nat Clin Pract Cardiovasc Med. 2006:3(2):80-5.

11. Lin C, Datta V, Okwan-Duodu D, Chen X, Fuchs S, Alsabeh R, et al. Angiotensin-converting enzyme is required for normal myelopoiesis. Faseb J. 2011;25(4):1145-55.

12. Haznedaroglu IC, Beyazit Y. Local bone marrow renin-angiotensin system in primitive, definitive and neoplastic haematopoiesis. Clin Sci (Lond). 2013;124(5):307-23.

13. Danser AH, Saris JJ, Schuijt MP, van Kats JP. Is there a local renin-angiotensin system in the heart? Cardiovasc Res. 1999; 44(2):252-65.

14. Dostal DE, Baker KM. The cardiac renin-angiotensin system: conceptual, or a regulator of cardiac function? Cardiovasc Res. 1999;85(7):643-50.

15. Holtz J, Goetz RM. Vascular renin-angiotensin-system, endothelial function and atherosclerosis? Basic Res Cardiol. 1994; 89:71-86.

16. Paul M, Stock P, Langheinrich M, Liefeldt L, Schonfelder G, Bohm M. Role of the cardiac renin-angiotensin system in human heart failure. Adv Exp Med Biol. 1995;377:279-83. 
17. Valdivielso JM, Rodriguez-Puyol D, Pascual J, Barrios C, Bermudez-Lopez M, Sanchez-Nino MD, et al. Atherosclerosis in chronic kidney disease: more, less, or just different? Arterioscler Thromb Vasc Biol. 2019;39(10):1938-66.

18. Platten M, Youssef S, Hur EM, Ho PP, Han MH, Lanz TV, et al. Blocking angiotensin-converting enzyme induces potent regulatory $\mathrm{T}$ cells and modulates TH1- and TH17-mediated autoimmunity. Proc Natl Acad Sci U S A. 2009; 106(35):14948-53.

19. Jurewicz M, McDermott DH, Sechler JM, Tinckam K, Takakura A, Carpenter CB, et al. Human T and natural killer cells possess a functional renin-angiotensin system: further mechanisms of angiotensin II-induced inflammation. J Am Soc Nephrol. 2007;18(4):1093-102.

20. Song GG, Kim JH, Lee YH. Associations between the angiotensin-converting enzyme insertion/deletion polymorphism and susceptibility to sarcoidosis: a meta-analysis. J Renin-Angiotensin-Aldosterone Syst. 2015;16(1):219-26.

21. Ruiz-Ortega M, Bustos C, Hernandez-Presa MA, Lorenzo O, Plaza JJ, Egido J. Angiotensin II participates in mononuclear cell recruitment in experimental immune complex nephritis through nuclear factor-kappa B activation and monocyte chemoattractant protein-1 synthesis. J Immunol. 1998;161(1):430-9.

22. Rameshwar P, Ganea D, Gascon P. In vitro stimulatory effect of substance P on hematopoiesis. Blood. 1993;81(2):391-8.

23. Brice EA, Friedlander W, Bateman ED, Kirsch RE. Serum angiotensin-converting enzyme activity, concentration, and specific activity in granulomatous interstitial lung disease, tuberculosis, and COPD. Chest. 1995;107(3):706-10.

24. Baudin B. New aspects on angiotensin-converting enzyme: from gene to disease. Clin Chem Lab Med. 2002:40(3):256-65.

25. lannuzzi MC, Rybicki BA, Teirstein AS. Sarcoidosis. N Engl J Med. 2007;357(21):2153-65.

26. Stanton LA, Fenhalls G, Lucas A, Gough P, Greaves DR, Mahoney JA, et al. Immunophenotyping of macrophages in human pulmonary tuberculosis and sarcoidosis. Int J Exp Pathol. 2003;84(6):289-304.

27. Ulrich C, Seibert E, Heine GH, Fliser D, Girndt M. Monocyte angiotensin converting enzyme expression may be associated with atherosclerosis rather than arteriosclerosis in hemodialysis patients. Clin J Am Soc Nephrol. 2011;6(3):505-11.

28. Ulrich C, Heine GH, Garcia P, Reichart B, Georg T, Krause M, et al. Increased expression of monocytic angiotensinconverting enzyme in dialysis patients with cardiovascular disease. Nephrol Dial Transplant. 2006;21(6):1596-602.

29. Okamura A, Rakugi H, Ohishi M, Yanagitani Y, Takiuchi S, Moriguchi K, et al. Upregulation of renin-angiotensin system during differentiation of monocytes to macrophages. J Hypertens. 1999;17(4):537-45.

30. Labandeira-Garcia JL, Rodriguez-Perez Al, Garrido-Gil P, Rodriguez-Pallares J, Lanciego JL, Guerra MJ. Brain reninangiotensin system and microglial polarization: implications for aging and Neurodegeneration. Front Aging Neurosci. 2017;9:129.

31. de Kloet AD, Liu M, Rodriguez V, Krause EG, Sumners C. Role of neurons and glia in the CNS actions of the reninangiotensin system in cardiovascular control. Am J Physiol Regul Integr Comp Physiol. 2015;309(5):R444-58.

32. Constantinescu CS, Goodman DB, Grossman RI, Mannon LJ, Cohen JA. Serum angiotensin-converting enzyme in multiple sclerosis. Arch Neurol. 1997;54(8):1012-5.

33. Griffing GT, Melby JC. Enalapril (MK-421) and the white cell count and haematocrit. Lancet. 1982;1(8285):1361.

34. Vlahakos DV, Canzanello VJ, Madaio MP, Madias NE. Enalapril-associated anemia in renal transplant recipients treated for hypertension. Am J Kidney Dis. 1991;17(2):199-205.

35. Gould AB, Goodman SA. Effect of an angiotensin-converting enzyme inhibitor on blood pressure and erythropoiesis in rats. Eur J Pharmacol. 1990;181(3):225-34.

36. Hirakata H, Onoyama K, Iseki K, Kumagai H, Fujimi S, Omae T. Worsening of anemia induced by long-term use of captopril in hemodialysis patients. Am J Nephrol. 1984;4(6):355-60.

37. Sica DS. Pharmacotherapy in congestive heart failure: ACE inhibitors and anemia in congestive heart failure. Congest Heart Fail. 2000;6(6):330-2.

38. Hashmi HR, Jabbour R, Schreiber Z, Khaja M. Benazepril-induced Agranulocytosis: a case report and review of the literature. Am J Case Rep. 2016;17:425-8.

39. Strawn WB, Richmond RS, Ann Tallant E, Gallagher PE, Ferrario CM. Renin-angiotensin system expression in rat bone marrow haematopoietic and stromal cells. Br J Haematol. 2004;126(1):120-6.

40. Jokubaitis VJ, Sinka L, Driessen R, Whitty G, Haylock DN, Bertoncello I, et al. Angiotensin-converting enzyme (CD143) marks hematopoietic stem cells in human embryonic, fetal, and adult hematopoietic tissues. Blood. 2008;111(8):4055-63.

41. Zambidis ET, Park TS, Yu W, Tam A, Levine M, Yuan X, et al. Expression of angiotensin-converting enzyme (CD143) identifies and regulates primitive hemangioblasts derived from human pluripotent stem cells. Blood. 2008;112(9):3601-14.

42. Azizi M, Rousseau A, Ezan E, Guyene TT, Michelet S, Grognet JM, et al. Acute angiotensin-converting enzyme inhibition increases the plasma level of the natural stem cell regulator N-acetyl-seryl-aspartyl-lysyl-proline. J Clin Invest. 1996;97(3): 839-44.

43. Li J, Volkov L, Comte L, Herve P, Praloran V, Charbord P. Production and consumption of the tetrapeptide AcSDKP, a negative regulator of hematopoietic stem cells, by hematopoietic microenvironmental cells. Exp Hematol. 1997;25(2):140-6.

44. Robinson S, Lenfant M, Wdzieczak-Bakala J, Melville J, Riches A. The mechanism of action of the tetrapeptide acetyl-NSer-asp-Lys-pro (AcSDKP) in the control of haematopoietic stem cell proliferation. Cell Prolif. 1992;25(6):623-32.

45. Rousseau-Plasse A, Lenfant M, Potier P. Catabolism of the hemoregulatory peptide N-acetyl-Ser-asp-Lys-pro: a new insight into the physiological role of the angiotensin-I-converting enzyme N-active site. Bioorg Med Chem. 1996;4(7): 1113-9.

46. Comte L, Lorgeot V, Volkov L, Allegraud A, Aldigier JC, Praloran V. Effects of the angiotensin-converting enzyme inhibitor enalapril on blood haematopoietic progenitors and acetyl-N-Ser-asp-Lys-pro concentrations. Eur J Clin Investig. 1997:27(9):788-90.

47. Rodgers KE, Xiong S, Steer R. diZerega GS. Effect of angiotensin II on hematopoietic progenitor cell proliferation. Stem Cells. 2000;18(4):287-94.

48. Chisi JE, Wdzieczak-Bakala J, Thierry J, Briscoe CV, Riches AC. Captopril inhibits the proliferation of hematopoietic stem and progenitor cells in murine long-term bone marrow cultures. Stem Cells. 1999;17(6):339-44.

49. Kolaczkowska E, Kubes P. Neutrophil recruitment and function in health and inflammation. Nat Rev Immunol. 2013;13(3): 159-75.

50. Amulic B, Cazalet C, Hayes GL, Metzler KD, Zychlinsky A. Neutrophil function: from mechanisms to disease. Annu Rev Immunol. 2012;30:459-89. 
51. Arndt PG, Young SK, Poch KR, Nick JA, Falk S, Schrier RW, et al. Systemic inhibition of the angiotensin-converting enzyme limits lipopolysaccharide-induced lung neutrophil recruitment through both bradykinin and angiotensin IIregulated pathways. J Immunol. 2006;177(10):7233-41.

52. Khan Z, Shen XZ, Bernstein EA, Giani JF, Eriguchi M, Zhao TV, et al. Angiotensin-converting enzyme enhances the oxidative response and bactericidal activity of neutrophils. Blood. 2017;130(3):328-39.

53. Molinaro G, Cugno M, Perez M, Lepage Y, Gervais N, Agostoni A, et al. Angiotensin-converting enzyme inhibitorassociated angioedema is characterized by a slower degradation of des-arginine (9)-bradykinin. J Pharmacol Exp Ther. 2002;303(1):232-7.

54. Prat A, Biernacki K, Saroli T, Orav JE, Guttmann CR, Weiner HL, et al. Kinin B1 receptor expression on multiple sclerosis mononuclear cells: correlation with magnetic resonance imaging T2-weighted lesion volume and clinical disability. Arch Neurol. 2005;62(5):795-800

55. Pouwels KB, Visser ST, Hak E. Effect of pravastatin and fosinopril on recurrent urinary tract infections. J Antimicrob Chemother. 2013;68(3):708-14.

56. Pouwels KB, Bos JH, Hak E. ACE inhibitors and urinary tract infections. Epidemiology. 2014;25(3):466-7.

57. Dial S, Nessim SJ, Kezouh A, Benisty J, Suissa S. Antihypertensive agents acting on the renin-angiotensin system and the risk of sepsis. Br J Clin Pharmacol. 2014;78(5):1151-8.

58. Kohlstedt K, Trouvain C, Namgaladze D, Fleming I. Adipocyte-derived lipids increase angiotensin-converting enzyme (ACE) expression and modulate macrophage phenotype. Basic Res Cardiol. 2011;106(2):205-15.

59. Diet F, Pratt RE, Berry GJ, Momose N, Gibbons GH, Dzau VJ. Increased accumulation of tissue ACE in human atherosclerotic coronary artery disease. Circulation. 1996;94(11):2756-67.

60. Saijonmaa O, Nyman T, Fyhrquist F. Atorvastatin inhibits angiotensin-converting enzyme induction in differentiating human macrophages. Am J Physiol Heart Circ Physiol. 2007;292(4):H1917-21.

61. Trojanowicz B, Ulrich C, Seibert E, Fiedler R, Girndt M. Uremic conditions drive human monocytes to pro-atherogenic differentiation via an angiotensin-dependent mechanism. PLoS One. 2014;9(7):e102137.

62. Shen XZ, Li P, Weiss D, Fuchs S, Xiao HD, Adams JA, et al. Mice with enhanced macrophage angiotensin-converting enzyme are resistant to melanoma. Am J Pathol. 2007;170(6):2122-34.

63. Okwan-Duodu D, Datta V, Shen XZ, Goodridge HS, Bernstein EA, Fuchs S, et al. Angiotensin-converting enzyme overexpression in mouse myelomonocytic cells augments resistance to Listeria and methicillin-resistant Staphylococcus aureus. J Biol Chem. 2010;285(50):39051-60.

64. Khan Z, Cao DY, Giani JF, Bernstein EA, Veiras LC, Fuchs S, et al. Overexpression of the C-domain of angiotensinconverting enzyme reduces melanoma growth by stimulating M1 macrophage polarization. J Biol Chem. 2019;294(12) 4368-80.

65. Galvan-Pena S, O'Neill LA. Metabolic reprograming in macrophage polarization. Front Immunol. 2014;5:420.

66. Cao DY, Spivia WR, Veiras LC, Khan Z, Peng Z, Jones AE, et al. ACE over expression in myeloid cells increases oxidative metabolism and cellular ATP. J Biol Chem. 2020;295(5):1369-84.

67. Danilov SM, Sadovnikova E, Scharenborg N, Balyasnikova IV, Svinareva DA, Semikina EL, et al. Angiotensin-converting enzyme (CD143) is abundantly expressed by dendritic cells and discriminates human monocyte-derived dendritic cells from acute myeloid leukemia-derived dendritic cells. Exp Hematol. 2003;31(12):1301-9.

68. Eisenlohr LC, Bacik I, Bennink JR, Bernstein K, Yewdell JW. Expression of a membrane protease enhances presentation of endogenous antigens to MHC class I-restricted T lymphocytes. Cell. 1992;71(6):963-72.

69. Scharfstein J, Monteiro AC, Schmitz V, Svensjo E. Angiotensin-converting enzyme limits inflammation elicited by Trypanosoma cruzi cysteine proteases: a peripheral mechanism regulating adaptive immunity via the innate kinin pathway. Biol Chem. 2008;389(8):1015-24.

70. Shen XZ, Billet S, Lin C, Okwan-Duodu D, Chen X, Lukacher AE, et al. The carboxypeptidase ACE shapes the MHC class I peptide repertoire. Nat Immunol. 2011;12(11):1078-85.

71. Shen XZ, Lukacher AE, Billet S, Williams IR, Bernstein KE. Expression of angiotensin-converting enzyme changes major histocompatibility complex class I peptide presentation by modifying C termini of peptide precursors. J Biol Chem. 2008;283(15):9957-65.

72. Hoch NE, Guzik TJ, Chen W, Deans T, Maalouf SA, Gratze P, et al. Regulation of T-cell function by endogenously produced angiotensin II. Am J Physiol Regul Integr Comp Physiol. 2009;296(2):R208-16.

73. Silva-Filho IL, Souza MC, Ferreira-Dasilva CT, Silva LS, Costa MF, Padua TA, et al. Angiotensin II is a new component involved in splenic T lymphocyte responses during Plasmodium berghei ANKA infection. PLoS One. 2013;8(4):e62999.

74. De Smet D, Martens GA, Berghe BV, Meysman M, Heylen O, Gorus FK, et al. Use of likelihood ratios improves interpretation of laboratory testing for pulmonary sarcoidosis. Am J Clin Pathol. 2010;134(6):939-47.

75. Mroz RM, Korniluk M, Stasiak-Barmuta A, Chyczewska E. Upregulation of Th1 cytokine profile in bronchoalveolar lavage fluid of patients with hypersensitivity pneumonitis. J Physiol Pharmacol. 2008;59:499-505.

\section{Publisher's Note}

Springer Nature remains neutral with regard to jurisdictional claims in published maps and institutional affiliations. 